\title{
Thermal Functionalization of Alkanes with Carbon Electrophiles
}

\author{
Yuxin Gong, Lei Su, Zhaodong Zhu, Yang Ye and Hegui Gong* \\ Center for Supramolecular Chemistry and Catalysis, Department of Chemistry, Shanghai University, 99 Shang-Da Road, \\ Shanghai 200444, China
}

\begin{abstract}
Alkane functionalization with carbon-electrophiles remains virtually unexplored under thermo-driven hydrogen atom transfer (HAT) conditions due to a challenge of integrating oxidation and reduction in a single operation. We report here a Ni-catalyzed arylation and alkylation of alkane $\mathrm{C}-\mathrm{H}$ bonds with organohalides to forge $\mathrm{C}\left(\mathrm{sp}^{3}\right)-\mathrm{C}$ bonds by merging easily accessible $\mathrm{Zn}$ and $t \mathrm{BuOO} t \mathrm{Bu}(\mathrm{DTBP})$ as the external reductant and oxidant. The mild and easy-to-operate protocol enables facile carbofunctionalization of $\mathrm{N}-/ \mathrm{O}-\alpha$ - and cyclohexane $\mathrm{CH}$ bonds, and preparation of a number of bioactive compounds and drug derivatives. Preliminary mechanistic studies implied a Ni(I)-mediated DTBP reduction followed by alkane HAT to tBuO radical. The marked compatibility of Zn and DTBP with nickel-catalysis may invoke the development of external oxidant and reductant co-trigged thermoredox bond forming approaches based upon challenging substrates.
\end{abstract}

\section{Introduction}

Alkanes are abundant chemical feedstocks that have versatile uses as fuel, lubricating oils and raw materials in chemical and pharmaceutical industry. Considerable synthetic approaches building upon the state-of-the-art functionalization of alkane $\mathrm{C}-\mathrm{H}$ bonds have been developed to afford value-added $\mathrm{C}\left(\mathrm{sp}^{3}\right)$-based chemical bonds ${ }^{1-3}$. Nevertheless, construction of $\mathrm{C}\left(\mathrm{sp}^{3}\right)-\mathrm{C}$ bonds via transition-metal-catalyzed $\mathrm{C}\left(\mathrm{sp}^{3}\right)-\mathrm{H}$ bond coupling with carbon-electrophiles under thermal conditions remains a formidable challenge ${ }^{4-6}$. In the catalytic $2 \mathrm{e}^{-}$coupling reactions, a directing group is generally required to trigger the $\mathrm{C}\left(\mathrm{sp}^{3}\right)-\mathrm{H}$ bond activation (Fig. 1a) $)^{6}$. Alternatively, the photo-induced alkane hydrogen-atom transfer (HAT) mediated by a catalytic excited oxidant has permitted a wide spectrum of $\mathrm{C}\left(\mathrm{sp}^{3}\right)-\mathrm{H}$ bonds to couple with carbon-electrophiles by merging with reductive Ni-catalysis (Fig. 1b). ${ }^{7-10}$ To our knowledge, a HAT-provoked transition-metal-catalyzed alkane/carbon-electrophile coupling process remains unexplored under thermal conditions ${ }^{11}$, likely due to the lack of a ground-state oxidant that is compatible with catalytic reductive coupling process. Herein, we disclose that use of di-tBu-peroxide (DTBP) as the HAT oxidant and $\mathrm{Zn}$ as the reductant enables Ni-catalyzed thermal functionalization of a broad range of alkane $\mathrm{C}\left(\mathrm{sp}^{3}\right) \mathrm{H}$ bonds with organohalides to forge $\mathrm{C}\left(\mathrm{sp}^{3}\right)-\mathrm{C}$ bonds. The method allows facile preparation and diversification of drug intermediates and bioactive compounds, and is easy to run at 10-gram scale.

Our strategy for advancing the thermal alkane $\mathrm{CH} /$ electrophile coupling method lies in integrating external oxidant and reductant with Ni-catalysis. The mechanistic hypothesis stresses that an oxidant incites alkane HAT to give an alkyl radical, whereas the reductant dictates the Ni-catalyzed reductive coupling path (Fig. 1c) ${ }^{12-13}$. As such, a radical-chain mechanism operates through trapping the alkyl radical with a Ni intermediate preceding formation of a key $\mathrm{C}\left(\mathrm{sp}^{3}\right)-\mathrm{Ni}^{\mathrm{III}}-\mathrm{C}$ species (Fig. 1c) ${ }^{14-16}$. Obstacles impeding this proposal are obvious. First, coexistence of a strong reductant and a strong oxidant could lead to spontaneous self-consumption of the two active species, thus terminating the coupling process. Second, the presence of stoichiometric amount of oxidant may 
severely interfere with the reductive coupling process, as seen in the Ni-catalyzed cross-electrophile coupling reactions that are routinely operated under inert atomosphere ${ }^{17-18}$.

In this work, the remarkable compatibility of economic DTBP $(\$ 169 / 1 \mathrm{~L}$, Aldrich) and Zn with earth-abundant $\mathrm{Ni}$ catalysis secured the development of $\mathrm{C}\left(\mathrm{sp}^{3}\right) \mathrm{H} / \mathrm{C}$-electrophile coupling reaction. Based upon our preliminary mechanistic studies, we propose a $\mathrm{L}_{\mathrm{n}} \mathrm{Ni}^{\mathrm{I}}$-directed reduction of DTBP to produce $t \mathrm{BuO}$ radical for alkane HAT. The resultant alkyl radical is thought to be intercepted by $\mathrm{LnNi}_{n} \mathrm{Ni}_{2}$ rather than the commonly proposed $\mathrm{Ar}-\left(\mathrm{L}_{\mathrm{n}}\right) \mathrm{Ni}^{\mathrm{II}} \mathrm{X}$ and $\mathrm{L}_{\mathrm{n}} \mathrm{Ni}^{0}$ species, affording a C $\left(\mathrm{sp}^{3}\right)-\mathrm{Ni}^{\mathrm{III}} \mathrm{X}_{2}$ intermediate (Fig. 1c, routes A vs B \& C) ${ }^{13-16}$. Subsequent $\mathrm{Zn}$ reduction followed by oxidative addition of an electrophile to the resultant $\mathrm{C}\left(\mathrm{sp}^{3}\right)-\left(\mathrm{L}_{\mathrm{n}}\right) \mathrm{Ni}^{\mathrm{I}}$ intermediate furnishes a key $\mathrm{C}\left(\mathrm{sp}^{3}\right)-\mathrm{Ni}^{\mathrm{III}}-\mathrm{C}$ species prior to product omission.

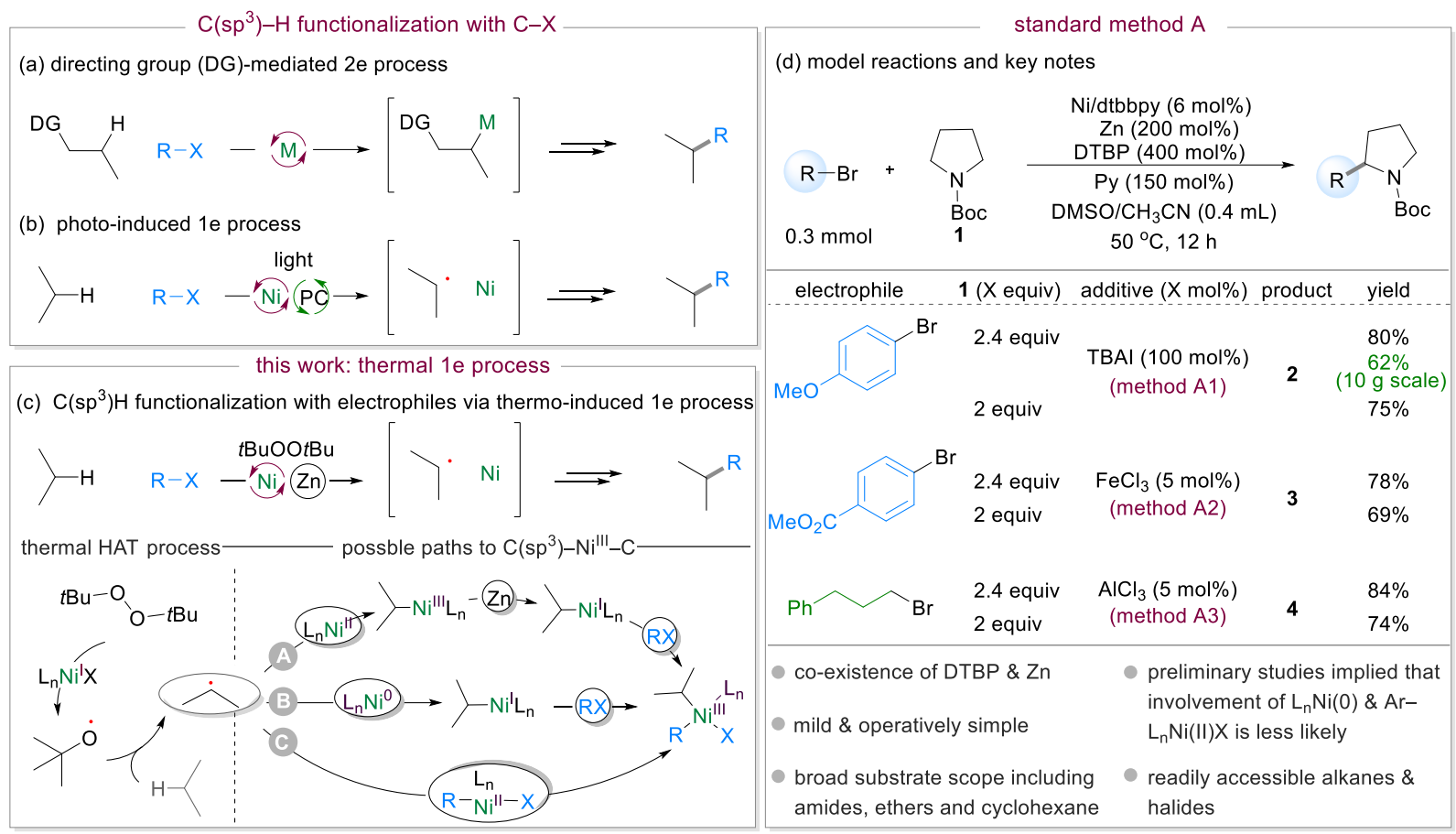

Fig. 1. Methods of redox coupling of $\mathrm{C}\left(\mathrm{sp}^{3}\right) \mathrm{H}$ with $\mathrm{C}$-electrophiles. Left Boxes: Known methods $(\mathrm{a}$ and $\mathrm{b})$ and design of thermal 1e $\mathrm{C}\left(\mathrm{sp}^{3}\right) \mathrm{H}$ redox coupling (c, this work). Right Box: the standard method A for the coupling of 1 with organobromides (d).

\section{Result and Discussion}

Our studies commenced with an examination of the coupling of 1 with methyl 4-bromoanisole. Extensive optimization led to the coupling product 2 in an optimal $80 \%$ yield using $\mathrm{Ni}(\mathrm{dtbbpy}) \mathrm{Br}_{2}$ as precatalyst, pyridine and TBAI as additives, in the presence of 2 equiv of Zn and 4 equiv of DTBP when 2.4 equiv of 1 was employed (method A1, Fig. 1d) ${ }^{19}$. The reaction was conveniently run at gram and 10-gram scales, affording 2 in $73 \%$ and $62 \%$ yields, respectively. In the latter case, $\sim 1.4$ equiv (58\%) of 1 and $\sim 1$ equiv (50\%) of $\mathrm{Zn}$ can be recovered, implying potential applicability of the method (Fig. 1d). By replacing TBAI, $\mathrm{FeCl}_{3}$ and $\mathrm{AlCl}_{3}(5 \mathrm{~mol} \%$ ) were independently used to promote the coupling of 1 with electron-deficient methyl 4-bromobenzaote (method A2), and with 1-bromopropylbenzene (method A3), affording 3 and 4 in $78 \%$ and $84 \%$ yields, respectively ${ }^{19}$. In the three 
cases, the yields dropped by 5-10\% with 2 equiv of 1 (Fig. 1d). The noninnocent roles of TBAI and $\mathrm{FeCl}_{3}$ in promoting the consumption of aryl bromides (Tables S1 \& S5) were tentatively ascribed to that TBAI homogenized the reaction mixture, and $\mathrm{FeCl}_{3} / \mathrm{Zn}$ augmented the conversion of DTBP to $t \mathrm{BuO}$ radical with $\mathrm{Fe}^{\mathrm{II}}$ formed in $\mathrm{situ}^{3}$, respectively. The presence of $5 \%$ of $\mathrm{AlCl}_{3}$ in method $\mathrm{C}$ considerably suppressed dimerization of alkyl halides (Scheme S2); the reason is not clear in this time.

The established coupling method proved be compatible with a diverse set of aryl halides as evidenced by their coupling with 1 to afford 5-28 (Fig. 2). A myriad of functional groups, such as $\mathrm{CF}_{3}(\mathbf{5})$, amide (7), ether (8), fluorine and chlorine (11-13), acetal (14), Bpin (18) and phenol (19) were tolerated. Compound 12 could be a core intermediate to $( \pm)$-larorectinib. Varying the substitution patterns of bromoanisoles did not affect the coupling yields as displayed by the examples of 9-10. The coupling efficiency for 15-17 declined with ortho-methyl, cyanomethyl and -ethyl bromobenzene being the substrates. The conjugated 9-bromophenanthrene resulted in 20 in $60 \%$ yield. The heteroaryl halides were also examined, wherein products containing 5- and 4-pyridyl derivatives (21-25), as well as 5-benzo[b]thiophene (26), 6-quinoline (27), and protected 5-indoles (28) were obtained in moderate to good yields. A number of primary and secondary alkyl halides used as coupling partners with 1 gave 29-35 in good yields.

The scope of amides was examined next by first coupling with methyl 4-bromoanisole. The Boc- and $t$ butylaminocarbonyl (Bac)-protected 4-, 5-, 6- and 7-membered cyclic amines were effective as manifested by the examples of 36-42. 1,3-Dimethylimidazolidin-2-one afforded $\mathbf{4 3}$ along with a regioisomer arising from the methyl site in a total $61 \%$ yield and a 1.5:1 regioselective ratio (rr), whereas 1,1,3,3-tetramethylurea converted into 44 in a moderate yield. The coupling efficiencies for Boc- and Bac-protected dialkyl amines were satisfactory, affording 45-47 in reasonably good yields. Arylation of $N$-methylpentan-1-amine slightly favored at the sterically less-hindered $\mathrm{C} 1$ site to give $\mathbf{4 8}$ and a $\mathrm{C} 2$-product in a 1.8:1 rr. For $N, N$-dimethylaniline, diarylation occurred preferentially giving 49 in $80 \%$ yield. The use of Bac as a protecting group seemed to be more effective than Boc for primary amines, as manifested by the examples of $\mathbf{5 0}$ and 51. Arylation of an oxygen-capped primary amine delivered 52 in a moderate yield. Alkylation of the open-chain and cyclic amines were viable as seen by the examples of 53-55. The utility of the present $\mathrm{CH}$ carbofunctionalization methodology was showcased by facile preparation of the key precursors of drug and bioactive compounds and analogs, as exemplified by $\mathbf{5 6}$ whose cisisomer is a core intermediate for sodium channel blocker vixorigine ${ }^{20}, \mathbf{5 7}$ for $( \pm)$-cuspareine and $\mathbf{5 8}$ for an estrogen receptor ${ }^{21}$. The method was also effective for late-stage functionalization of drug compounds by introduction of 2-pyrrolidine to indomethacine (59) and a butyl amide to clofibrate (60). 


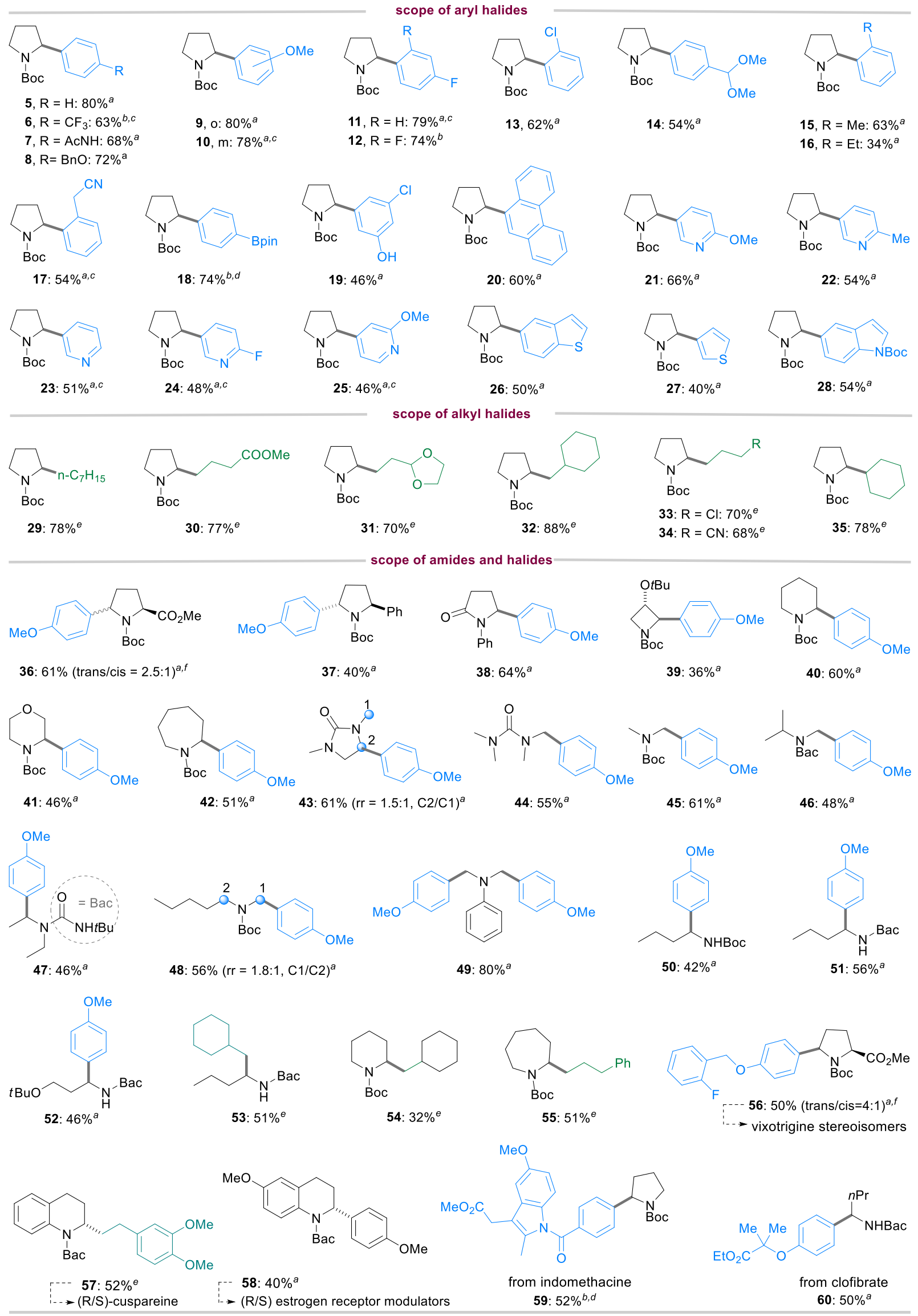

Fig. 2. Scope of amides and carbon electrophiles. ${ }^{a}$ Method A1 used. ${ }^{b}$ method A2 used. ${ }^{c}$ The reaction was performed at $70{ }^{\circ} \mathrm{C} .{ }^{d} \mathrm{Ni}(\mathrm{acac})_{2}$, TBAI and NCS instead of $\mathrm{NiBr}_{2}$ and pyridine. ${ }^{e}$ method $\mathrm{A} 3$ used. ${ }^{f} 3$ equiv of $N-\alpha-\mathrm{CH}$ was used. 
The $\mathrm{CH}$ redox coupling conditions were extendable to $\mathrm{O}-\alpha-\mathrm{CH}$ bonds (Fig. 3) ${ }^{22-24}$. Exposure of 6 equiv. of tetrahydrofuran (THF) to 4-bromoanisole and methyl 4-bromobenzoate delivered $\mathbf{6 1}$ and $\mathbf{6 2}$ in $55 \%$ and $66 \%$ yields, respectively. Using THF as the coupling partners, the scope of aryl bromides proved to be broad regardless of the electronic properties of the electrophiles as shown by the examples of 63-67. A much enhanced yield was observed for 68 containing a 2-MeO group, possibly owing to auxiliary chelation of the methoxy with Ni. The reaction also displayed good compatibility with 9-bromophenanthrene (69), 6-bromoquinoline (70) and a few 4- and 5-bromopyridines substituted by 2-Me, $-\mathrm{CF}_{3}$, -OMe and $-\mathrm{F}$ as illustrated by $\mathbf{7 1 - 7 4}$, as well as 5-bromoindole (75) and 5-bromobenzo[b]thiophene (76). In comparison, 1-bromopropylbenzene was less effective than the aryl counterparts, affording 77 in $44 \%$ yield.

A brief survey of the scope of $\mathrm{O}-\alpha-\mathrm{CH}$ substrates showed that 1,6-dioxane, 1,3-dioxolane, 2methyltetrahydrofuran, oxetane and diethyl ether were all competent for the coupling with 2-bromoanisole and/or methyl 4-bromobenzoate as showcased by the examples of 78-84. A regioisomer associated with $\mathbf{8 1}$ and a low dr for $\mathbf{8 2}$ were detected. Finally, by slight modification of method A2 with addition of NCS, the coupling of 10 equiv of cyclohexane with methyl 4-bromobenzoate furnished $\mathbf{8 5}$ in $51 \%$ yield, demonstrating promise of the present method for the coupling of strong $\mathrm{C}\left(\mathrm{sp}^{3}\right)-\mathrm{H}$ bonds $\mathrm{s}^{25-26}$.



61: $\mathrm{R}=\mathrm{MeO}: 55 \%$

62: $\mathrm{R}=\mathrm{CO}_{2} \mathrm{Me}: 66 \%$

63: $\mathrm{R}=\mathrm{AcNH}: 70 \%$

64: $\mathrm{R}=\mathrm{H}: 51 \%$

65: $R=A C: 57 \%$

66: $\mathrm{R}=\mathrm{F}: 51 \%$

67: $\mathrm{R}=\mathrm{CF}_{3}: 37 \%(51 \%)^{\mathrm{a}}$

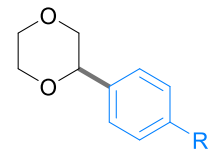

78: $\mathrm{R}=\mathrm{OMe}: 65 \%\left(70{ }^{\circ} \mathrm{C}\right)$

79: $\mathrm{R}=\mathrm{CO}_{2} \mathrm{Me}: 50 \%$

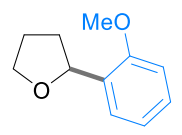

68: $76 \%$

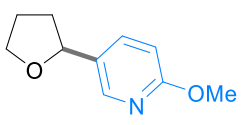

73: $56 \%(66 \%)^{a}$



80: $R=$ OMe: $62 \%$ (single isomer)

81: $\mathrm{R}=\mathrm{CO}_{2} \mathrm{Me}: 56 \%(\mathrm{rr}=5: 1)$

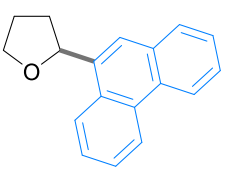

69: $68 \%$

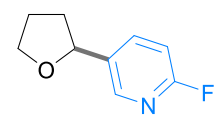

74: $66 \%$

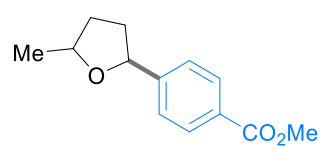

82: $41 \%^{b}(d r=1.7: 1)$

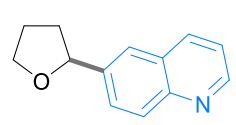

70: $42 \%$



75: $50 \%$

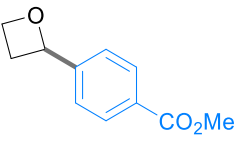

83: $43 \%^{a}$

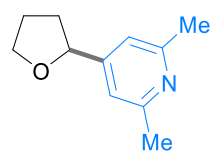

71: $33 \%(42 \%)^{a}$



76: $51 \%$
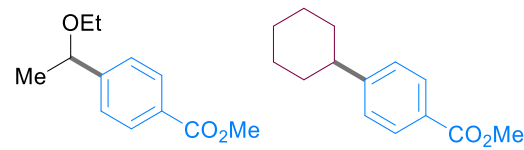

84: $48 \%\left(25^{\circ} \mathrm{C}\right)^{\mathrm{a}}$

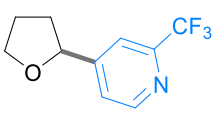

72: $42 \%$



77: $42 \%^{a}$

85: $51 \%^{b, c}$

Fig. 3. Coupling of $\mathrm{O}-\alpha-\mathrm{CH}$ substrates. Unless otherwise noted, 6 equiv of $\mathrm{O}-\alpha-\mathrm{CH}$ was used with method A (Fig. 1d). ${ }^{a} 8$ equivs of $\mathrm{O}-\alpha-\mathrm{CH}$ were used. ${ }^{b} \mathrm{Ni}(\mathrm{acac})_{2}$, TBAI $(100 \%)$ and $\mathrm{NCS}(30 \%)$ instead of $\mathrm{NiBr}_{2}$ and py. ${ }^{c} 10$ equiv of cyclohexane was used in the presence of NCS (30\%) with method A2.

\section{Mechanistic studies}

A key mechanistic speculation of the present work is the involvement of alkyl radial via alkane HAT to $t \mathrm{BuO}$ radical generated by 1 e reduction of TDBP with $\mathrm{Ni} / \mathrm{Zn}$. The radical nature of the reaction was confirmed by the reactions of THF with (1-cyclopropylvinyl)benzene, and 1 with bromocyclopropylmethane, wherein the cyclopropyl ring-opening products $\mathbf{8 6}$ and $\mathbf{8 7}$ were detected (Fig. 4a). A deliberately designed radical cyclization of $\mathbf{8 8}$ was not observed; rather a $\mathrm{CH}$ arylation product $\mathbf{8 9}$ was produced, hinting the latter process is kinetically more facile (Fig. 4a). Tracking the reaction progress of 1 with 4-bromoanisole indicated slow consumption of DTBP; 
$\sim 40 \%$ of DTBP remained intact after 8 hours (Fig. S1) ${ }^{19}$. Exposure of DTBP to a mixture of $\mathrm{Zn}$ and (dtbbpy) $\mathrm{NiBr}_{2}$ in DMSO at $50{ }^{\circ} \mathrm{C}$ resulted in appreciable amount of $t \mathrm{BuOH}$ and acetone after $1 \mathrm{~h}$ (Figs. 4b, S19), indicative of formation of $t \mathrm{BuO}$ radical ${ }^{27}$, likely due to reduction of DTBP with putative (dtbbpy) $\mathrm{Ni}^{\mathrm{I} B r} \mathbf{I}-\mathbf{1}$ generated by reduction of (dtbbpy) $\mathrm{NiBr}_{2}$ with $\mathrm{Zn} .{ }^{28} \mathrm{By}$ contrast, $\mathrm{Zn}$ or (dtbbpy) $\mathrm{NiBr}_{2}$ alone did not react with DTBP, nor was (dtbbpy) $\mathrm{Ni}^{0}(\mathrm{COD}) / \mathrm{Zn}$ or $\left[(\mathrm{dtbbpy}) \mathrm{Ni}^{\mathrm{I}} \mathrm{Cl}\right]_{2}[\mathbf{I}-\mathbf{1}]_{2}$ (Figs. $\left.4 \mathrm{~b}-\mathrm{c}, \mathrm{S} 14-21\right)^{19}$. [I-1 $]_{2}$ is a strong reductant $\left(\mathrm{E}_{1 / 2}{ }^{\mathrm{red}}=-1.4 \mathrm{~V} \text { in } \mathrm{CH}_{3} \mathrm{CN} \text { vs } \mathrm{SCE}\right)^{29}$, but is much less reactive than monomeric $\mathbf{I}-\mathbf{1}$ in the instances involving inner sphere transformations that may also take place for peroxide reduction ${ }^{30}$. $[\mathbf{I}-\mathbf{1}]_{2}$ decomposed rapidly in DMSO giving a similar ${ }^{1} \mathrm{H}$ NMR spectra to that of (dtbbpy) $\mathrm{NiBr}_{2}$ that suffered from partial decomposition in DMSO (Figs. 4d, S2, S9-S12) ${ }^{19}$, which may also explain why DTBP was inert to [I-1 $]_{2}$.
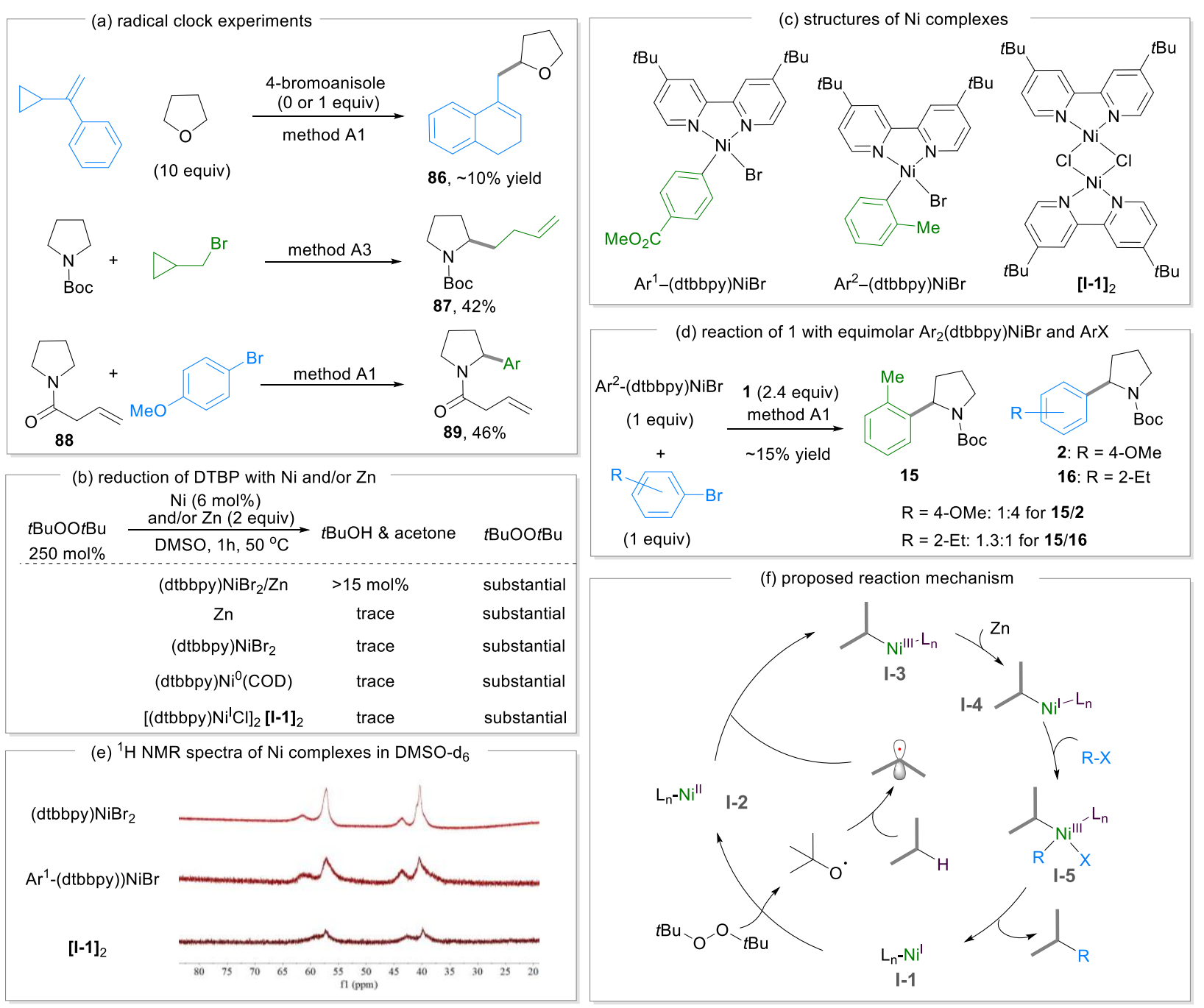

Figure 4. Mechanistic studies and a proposed reaction mechanism.

Trapping an alkyl radical by $\mathrm{Ni}(0)$ or $\mathrm{Ar}-\mathrm{Ni}^{\mathrm{II}} \mathrm{X}$ has been proposed in Ni-catalyzed coupling reactions ${ }^{13-15}$. A set of control experiments uncovered that both species were less likely involved in the reaction. Treatment of (dtbbpy) $\mathrm{NiBr}_{2}$ with $\mathrm{Zn}$ in the absence or presence of DTBP in DMSO did not lead to detectable amount of (dtbbpy)Ni(0) (Figs S15, S19) ${ }^{19}$. Next, reaction of $\mathbf{1}$ with equimolar mixture of 4-bromoanisle and $\mathrm{Ar}^{2}-$ (dtbbpy) $\mathrm{Ni}^{\mathrm{II}} \mathrm{Br}$ that is stable in DMSO with method A resulted in $\mathbf{2}$ and $\mathbf{1 5}$ in a 4:1 ratio, whereas the much 
sterically congested 2-ethyl bromobenzene gave 15 and 16 in a 1:1 ratio (Fig. 4d). Thus, formation of 2 and 16 largely through in situ conversion of $\mathrm{ArX}$ to $\mathrm{ArNi}^{\mathrm{II} X}$ can be excluded, considering that generation of $\mathbf{1 5}$ from the preformed $\mathrm{Ar}^{2}-(\mathrm{dtbbpy}) \mathrm{Ni}^{\mathrm{II}} \mathrm{Br}$ at much higher concentrations was less competing. Moreover, the sterically less hindered $\mathrm{Ar}^{1}-(\mathrm{dtbbpy}) \mathrm{Ni}^{\mathrm{II}} \mathrm{Br}$ decomposed instantaneously in DMSO, and displayed similar paramagnetic NMR spectra to that of (dtbbpy) $\mathrm{NiBr}_{2}$, which further supported that $\mathrm{ArN}^{\mathrm{II} X}$ is less likely a key intermediate in the catalytic reaction (Figs. 4e, S2-4) ${ }^{19}$.

In line with the above studies, we proposed a catalytic path that involves reduction of DTBP with a $\mathrm{L}_{n} \mathrm{Ni}^{\mathrm{I}}$ species $\mathbf{I}-\mathbf{1}$ to afford $t \mathrm{BuO}$ radical accompanying a $\mathrm{L}_{\mathrm{n}} \mathrm{N}^{\mathrm{II}}$ intermediate $\mathbf{I}-\mathbf{2}$. Alkane HAT to $t \mathrm{BuO}$ radical results in an alkyl radical that is intercepted by $\mathbf{I}-2$ to furnish $\mathrm{C}\left(\mathrm{sp}^{3}\right)-\mathrm{L}_{\mathrm{n}} \mathrm{Ni}^{\mathrm{III}}$ intermediate $\mathbf{I - 3}$, which is reduced by $\mathrm{Zn}$ to generate $\mathrm{C}\left(\mathrm{sp}^{3}\right)-\mathrm{L}_{\mathrm{n}} \mathrm{Ni}^{\mathrm{I}}$ complex $\mathbf{I}-\mathbf{4}$. Oxidative addition of a carbon-halide to $\mathbf{I}-\mathbf{4}$ results in $\mathrm{C}\left(\mathrm{sp}^{3}\right)-\mathrm{L}_{\mathrm{n}} \mathrm{Ni}{ }^{\mathrm{III}}-\mathrm{C}$ intermediate $\mathbf{I}-\mathbf{5}$. Upon reductive elimination, the $\mathrm{C}\left(\mathrm{sp}^{3}\right)-\mathrm{C}$ product is produced in conjunction with $\mathrm{L}_{\mathrm{n}} \mathrm{Ni}^{\mathrm{I}}$ species $\mathbf{I}-\mathbf{1}$, allowing the catalytic cycle to continue (Fig. 4f). As supported by the example of 87, oxidative addition of an alkyl halide to I-4 may proceed through inner sphere halide abstraction to give alkyl radical and $\mathrm{C}\left(\mathrm{sp}^{3}\right)-\mathrm{L}_{\mathrm{n}} \mathrm{Ni}^{\mathrm{II}}$ intermediate I-6 in a solvent cage, prior to their rapid combination to give I-5 (Scheme S7) ${ }^{31}$.

\section{Conclusion}

In summary, we have established a Ni-catalyzed $\mathrm{C}\left(\mathrm{sp}^{3}\right)-\mathrm{C}$ bond forming protocol through arylation and alkylation of alkanes with organohalides under mild thermal conditions that are mediated by Zn and DTBP. A wide range of $\mathrm{N}-/ \mathrm{O}-\alpha-\mathrm{CH}$ substrates and cyclohexane were accommodated. The practicality of this work was manifested by an example of 10-gram-scale synthesis and by facile preparation and late-stage functionalization of bioactive and pharmaceutical compounds and their precursors. The proposed catalytic path highlights $t$ BuO radicalprovoked alkane HAT to alkyl radical that is trapped with a $\mathrm{Ni}^{\mathrm{II}}$ salt, followed by $\mathrm{Zn}$ reduction and oxidative addition of organohalides affording the key dicarbo- $\mathrm{Ni}^{\mathrm{III}}$ species. The distinctive features of this work underlines unanticipated marked compatibility of DTBP and Zn, allowing oxidation and reduction processes to operate independently under Ni-catalysis, thus offering a convenient handle for alkane functionalization under thermal conditions. It may sparkle development of new catalytic thermal coupling process based upon challenging substrates by merging exogenous oxidants and reductants in a single operation.

\section{Acknowledgements}

The authors acknowledge the financial support of the National Natural Science Foundation of China (21871173). We are grateful to Professors Yanghui Zhang (Tongji University), Xiaotai Wang (University of Colorado Denver) and Yunrong Chen (Shanghai Tech University) for advices, and Mr. Jiabo Wang for examination of part of the substrate scope.

\section{Author contributions}

HG designed the project. HG and YG and drafted the manuscript. Y.G, LS and ZZ performed the experiments. YY conducted the initial experiments. All the authors participated in preparation of the manuscript. 


\section{Competing interests}

The authors declare no competing financial interests.

\section{Additional information}

Supplementary information and compound characterization data are available in the online version of the paper. Reprints and permissions information is available online at www.nature.com/reprints.

Correspondence and requests for materials should be addressed to HG (E-mail: hegui_gong@shu.edu.cn)

\section{REFERENCES}

1. B. A. Arndtsen, R. G. Bergman, T. A. Mobley, T. H. Peterson. Selective intermolecular carbon-hydrogen activation by synthetic metal complexes in homogeneous solution. Acc. Chem. Res. 28, 154-162 (1995).

2. R. R. Karimov, J. F. Hartwig. Transition-Metal-Catalyzed Selective Functionalization of $\mathrm{C}\left(\mathrm{sp}^{3}\right)-\mathrm{H}$ Bonds in Natural Products. Angew. Chem. Int. Ed. 57, 4234- 4241 (2018).

3. C.-Y. Huang, H. Kang, J. Li, C.-J. Li. En Route to Intermolecular Cross-Dehydrogenative Coupling Reactions. J. Org. Chem. 84, 12705-12721 (2019).

4. J. He, M. Wasa, K. S. L. Chan, Q. Shao, Yu J.-Q. Yu. Palladium-Catalyzed Transformations of Alkyl C-H Bonds. Chem. Rev. 117, 8754-8786 (2017).

5. J. C. K. Chu, T. Rovis. Complementary Strategies for Directed C(sp3)-H Functionalization: A Comparison of Transition-Metal-Catalyzed Activation, Hydrogen Atom Transfer, and Carbene/Nitrene Transfer. Angew. Chem. Int. Ed. 57, 62 -101 (2018).

6. Z. Chen, M.-Y. Rong, J. Nie, X.-F. Zhu, B.-F. Shi, J.-A. Ma. Catalytic alkylation of unactivated C( $\left.\mathrm{sp}^{3}\right)-$ H bonds for $\mathrm{C}\left(\mathrm{sp}^{3}\right)-\mathrm{C}\left(\mathrm{sp}^{3}\right)$ bond formation. Chem. Soc. Rev., 48, 4921-4942 (2019).

7. L. Capaldo, D. Ravelli, M. Fagnoni. Direct Photocatalyzed Hydrogen Atom Transfer (HAT) for Aliphatic C-H Bonds Elaboration. Chem. Rev. 121 (2021). DOI: 10.1021/acs.chemrev.1c00263.

8. M. H. Shaw, V. W. Shurtleff, J. A. Terrett, J. D. Cuthbertson, D. W. C. MacMillan. Native Functionality in Triple Catalytic Cross-Coupling: sp3 C-H Bonds as Latent Nucleophiles. Science 352, 1304-1308 (2016).

9. A. Y. Chan, I. B. Perry, N. B. Bissonnette, B. F. Buksh, G. A. Edwards, L. I. Frye, O. L. Garry, M. N. Lavagnino, B. X. Li, Y. Liang, E. Mao, A. Millet, J. V. Oakley, N. L. Reed, H. A. Sakai, C. P. Seath, D. W. C. MacMillan, Metallaphotoredox: The Merger of Photoredox and Transition Metal Catalysis, Chem. Rev. 122, (2022), DOI: 10.1021/acs.chemrev.1c00383.

10. S. K. Kariofillis, A. G. Doyle. Synthetic and Mechanistic Implications of Chlorine Photoelimination in Nickel/Photoredox C(sp3 )-H Cross-Coupling, Acc. Chem. Res. 54, 988-1000 (2021).

11. R. Ueno, Y. Ikeda, E. Shirakawa. tert-Butoxy Radical-Promoted $\alpha$-Arylation of Alkylamines with Aryl Halides. Eur. J. Org. Chem. 4188-4193 (2017).

12. D. Liu, C. Liu, H. Li, A. Lei. Direct functionalization of tetrahydrofuran and 1,4-dioxane: nickel-catalyzed oxidative $\mathrm{C}\left(\mathrm{sp}^{3}\right)$-H arylation. Angew. Chem., Int. Ed. 52, 4453-4456 (2013).

13. S. Biswas, D. J. Weix. Mechanism and Selectivity in Nickel-Catalyzed Cross-Electrophile Coupling of Aryl Halides with Alkyl Halides. J. Am. Chem. Soc. 135, 16192-16197 (2013).

14. O. Gutierrez, J. C. Tellis, D.N. Primer, G. A. Molander, M. C. Kozlowski, Nickel-Catalyzed Cross-Coupling of Photoredox-Generated Radicals: Uncovering a General Manifold for Stereoconvergence in Nickel-Catalyzed Cross-Couplings, J. Am. Chem. Soc. 137, 4896-4899 (2015). 
15. S. A. Green, T. R. Huffman, R. O. McCourt, V. van der Puyl, R. A. Shenvi. Hydroalkylation of Olefins To Form Quaternary Carbons. J. Am. Chem. Soc. 141, 7709-7714 (2019).

16. B. Maity, C. Zhu, H. Yue, L. Huang, M. Harb, Y. Minenkov, M. Rueping, L. Cavallo. Mechanistic Insight into the Photoredox-Nickel-HAT Triple Catalyzed Arylation and Alkylation of $\alpha$-Amino $\mathrm{C}_{\mathrm{sp} 3}-\mathrm{H}$ Bonds, J. Am. Chem. Soc. 142, 16942-16952 (2020).

17. D. J. Weix. Methods and Mechanisms for Cross-Electrophile Coupling of Csp ${ }^{2}$ Halides with Alkyl Electrophiles. Acc. Chem. Res. 48, 1767-1775 (2015).

18. J. Liu, Y. Ye, J. L. Sessler, H. Gong. Cross-Electrophile Couplings of Activated and Sterically Hindered Halides and Alcohol Derivatives. Acc. Chem. Res. 53, 1833-1845 (2020).

19. See the supplementary information for details.

20. G. Giblin, A. Heseltine, W. Kiesman, D. MacPherson, J. Ramsden, R. Vadali, M. Williams, D. Witty. Synthesis of Vixotrigine, a Use-Dependent Sodium Channel Blocker. Part 1: Development of Bulk Supply Routes to Enable Proof of Concept. Org. Process Res. Dev. 24, 2802-2813 (2020).

21. S. C. Cosgrove, S. Hussain, N. J. Turner, S. P. Marsden. Synergistic Chemo/Biocatalytic Synthesis of Alkaloidal Tetrahydroquinolines. ACS Catal. 8, 5570-5573 (2018).

22. B. J. Shields, A. G. Doyle. Direct C(sp3)-H Cross Coupling Enabled by Catalytic Generation of Chlorine Radicals. J. Am. Chem. Soc. 138, 12719-12722 (2016).

23. D. R. Heitz, J. C. Tellis, G. A. Molander. Photochemical Nickel-Catalyzed C-H Arylation: Synthetic Scope and Mechanistic Investigations. J. Am. Chem. Soc. 138, 12715-12718 (2016).

24. Y. Shen, Y. Gu, R. Martin. $\mathrm{sp}^{3} \mathrm{C}-\mathrm{H}$ Arylation and Alkylation Enabled by the Synergy of Triplet Excited Ketones and Nickel Catalysts. J. Am. Chem. Soc. 140, 12200-12209 (2018).

25. L. K. G. Ackerman, J. I. Martinez Alvarado, A. G. Doyle. Direct C-C Bond Formation from Alkanes Using NiPhotoredox Catalysis. J. Am. Chem. Soc. 140, 14059-14063 (2018).

26. I. B. Perry, T. F. Brewer, P. J. Sarver. D. M. Schultz, D. A. DiRocco, D. W. C. MacMillan. Direct Arylation of Strong Aliphatic C-H Bonds. Nature 560, 70-75 (2018).

27. A. Vasilopoulos, S. W. Krska, S. S. Stahl. C( $\left.\mathrm{sp}^{3}\right)-\mathrm{H}$ methylation enabled by peroxide photosensitization and Nimediated radical coupling. Science 372, 398-403 (2021).

28. Q. Lin, T. Diao. Mechanism of Ni-Catalyzed Reductive 1,2-Dicarbofunctionalizationof Alkenes. J. Am. Chem. Soc. 141, 17937-17948 (2019).

29. M. M. Beromi, G. W. Brudvig, N. Hazari, H. M. C. Lant, B. Q. Mercado. Synthesis and Reactivity of Paramagnetic Nickel Polypyridyl Complexes Relevant to $\mathrm{C}\left(\mathrm{sp}^{2}\right)-\mathrm{C}\left(\mathrm{sp}^{3}\right)$ Coupling Reactions. Angew. Chem. Int. Ed. 58, $6094-6098$ (2019).

30. M. C. White, J. Zhao. Aliphatic C-H Oxidations for Late-Stage Functionalization. J. Am. Chem. Soc. 140, 13988-14009 (2018)

31. G. D. Jones, J. L. Martin, C. McFarland, O. R. Allen, R. E. Hall, A. D. Haley, R. J. Brandon, T. Konovalova, P. J. Desrochers, P. Pulay, D. A. Vicic. Ligand Redox Effects in the Synthesis, Electronic Structure, and Reactivity of an Alkyl-Alkyl Cross-Coupling Catalyst. J. Am. Chem. Soc. 128, 13175-13813 (2006). 